\title{
COBERTURA NITROGENADA EM GIRASSOL SOB PLANTIO DIRETO NA PALHA: I - RENDIMENTO DE GRÃOS E SEUS COMPONENTES, ÍNDICE DE COLHEITA E TEOR DE ÓLEO'
}

\author{
BROADCASTING NITROGEN IN NO-TILLAGE OF SUNFLOWER: \\ I - GRAIN YIELD AND ITS COMPONENTS, HARVEST INDEX AND OIL CONTENT
}

\author{
Denise Bruginski de CARVALHO \\ Amir PISSAIA ${ }^{2}$
}

\begin{abstract}
RESUMO
O trabalho teve como objetivo avaliar o efeito de diferentes doses de nitrogênio em cobertura no cultivo do girassol (Helianthus annuus L.) em sistema plantio direto na palha. O experimento foi conduzido no ano agrícola de 1998/99, na Fazenda Agripastos, em Palmeira, região dos Campos Gerais do Paraná, em um argissolo vermelho-amarelo, cultivado em sistema plantio direto na palha desde 1976. O delineamento experimental foi blocos ao acaso com quatro repetições. Os tratamentos foram: doses de nitrogênio $(0,25,50$, 75,100 e $125 \mathrm{~kg} \cdot \mathrm{ha}^{-1}$ ), na forma de uréia, aplicados em cobertura quando as plantas se encontravam no estádio $V_{8}$. O híbrido M734 foi semeado em setembro de 1998. Por ocasião da colheita, foram avaliados: rendimento de grãos, índice de colheita aparente, massa média de 1000 aquênios, número de aquênios por capítulo e teor de óleo nos aquênios. A adubação nitrogenada em cobertura, nas condições do experimento, não alterou rendimento de grãos, seus componentes e o teor de óleo nos aquênios.
\end{abstract}

Palavras-chave: Sistemas de cultura, Helianthus annuus L., matéria orgânica.

\begin{abstract}
This work was carried out in the agricultural year of 1998/99, with an objective to evaluate the effect of different levels of broadcasting nitrogen in the sunflower production (Helianthus annuus L.) in notillage system. The experiment was driven at Fazenda Agripastos, in Palmeira, region of Campos Gerais, Paraná, in a red-yellow argissol, cultived as no-tillage system since 1976. The experimental design used was a randomized completely blocks with four replications. The treatments were: rates of nitrogen $(0,25,50,75$, 100 and $125 \mathrm{~kg} \cdot \mathrm{ha}^{-1}$ ), in the urea form, applied in broadcast when the plants were met in the $\mathrm{V}_{8}$ stage. The hybrid M734 was sowed in September, 1998. The following parameters were evaluated: grain yield, apparent harvest index, weight of 1000 achenes, achenes number per capitulum and oil content in the achenes. The nitrogen fertilization in broadcast, in the conditions of the experiment, didn't present any increase in the grains and any changing in its components and the achene oil content.

Key-words: Crop system, Helianthus annuus L., organic matter.
\end{abstract}

\footnotetext{
${ }^{1}$ Extraído da dissertação de mestrado do primeiro autor, apresentada ao Curso de Pós-graduação em Agronomia - Produção Vegetal, Universidade Federal do Paraná.

${ }^{2}$ Engenheiro Agrônomo, CREA-PR 3480-D, Dr., professor adjunto do Departamento de Fitotecnia e Fitossanitarismo, Setor de Ciências Agrárias, UFPR.
} 
CARVALHO, D.B. e PISSAIA, A. Cobertura nitrogenada em girassol...

\section{INTRODUÇÃO}

O girassol (Helianthus annuus L.) é cultivado atualmente com o objetivo principal de obtenção de óleo, sendo importante não só pelo alto teor de óleo existente nos aquênios mas, principalmente, pelo alto índice de iodo, pela alta relação de ácidos graxos polinsaturados/saturados e pelo alto conteúdo de ácido graxo linoléico (3).

As culturas agrícolas de grande expressão econômica têm sido objeto principal de pesquisas relacionadas com o sistema plantio direto na palha, havendo necessidade de estudos com cultivos menos explorados, mas, que representem alternativas para rotação de culturas, como é o caso do girassol.

$O$ rendimento do girassol é função de diversas características agronômicas como diâmetro do capítulo, número de aquênios por capítulo, massa e teor de óleo nos aquênios que, interagindo entre si e com o ambiente, possibilitam a expressão do potencial genético da variedade utilizada $(23 ; 24)$.

São poucas as pesquisas que comparam o rendimento do girassol sob diferentes sistemas de cultivo. Os resultados obtidos indicam produção similar entre sistema de plantio direto e plantio convencional $(4 ; 5 ; 25)$.

A adubação nitrogenada constitui um fator importante na determinação do rendimento do girassol, sendo sua eficiência determinada pela dose e época de aplicação (29).

A ação do nitrogênio ocorre em todos os órgãos da planta, e a combinação das melhores doses e épocas de aplicação pode resultar em melhores rendimentos de grãos. O processo de absorção e acúmulo de nutrientes é dependente do sistema de cultivo empregado, além das características genéticas, de solo e de clima $(14 ; 17 ; 28)$.

A dinâmica do nitrogênio em um solo sob sistema plantio direto na palha depende da decomposição da matéria orgânica e envolve os processos de mineralização, imobilização, perdas por lixiviação e denitrificação, que com o passar do tempo determinam, devido ao equilíbrio atingido, a sua disponibilidade para as plantas $(12 ; 26)$.

Bayer e Scheneider (1) concluíram que a utilização do sistema plantio direto após anos de cultivo resulta no aumento dos teores de matéria orgânica entre 25 a $108 \%$ na camada $0-2,5 \mathrm{~cm}$ e de $18-52 \%$ na camada de $0-10 \mathrm{~cm}$ comparativamente ao preparo convencional. Segundo Kochhann (10) quando o teor de matéria orgânica atingir um equilíbrio dentro do sistema plantio direto, a disponibilidade de nitrogênio é normalizada. Teixeira et al. (26) trabaIhando com diferentes sistemas de culturas, concluíram que os sistemas que incluem plantas leguminosas determinam os maiores efeitos sobre a adição de nitrogênio no solo.

Do total de nitrogênio extraído, aproximadamente a metade é exportada para os aquênios. Como constituinte das proteínas acumuladas nos aquênios, o nitrogênio interage negativamente com a deposição de óleo, então doses elevadas de nitrogênio diminuem o teor de óleo nos aquênios $(9 ; 29)$.

Das fontes de nitrogênio disponíveis para aplicação em cobertura, a uréia é o fertilizante mais comercializado no país. Quando incorporado ao solo em profundidades entre 5 a $10 \mathrm{~cm}$, as perdas por volatilização são praticamente nulas (18).

Com a finalidade de comprovação formulouse a hipótese: se as características intrínsecas a um sistema de cultivo podem alterar a disponibilidade de nitrogênio para as plantas, então diferentes doses de nitrogênio aplicado nesse sistema de cultivo, tem efeito sobre o rendimento de grãos e seus componentes, índice de colheita aparente e teor de óleo nos aquênios.

O objetivo deste trabalho foi avaliar o efeito de doses de nitrogênio em cobertura no cultivo de girassol em sistema plantio direto na palha sobre rendimento de grãos e seus componentes, índice de coIheita aparente e teor de óleo nos aquênios.

\section{METODOLOGIA}

O experimento foi conduzido no ano agrícola de 1998/99, na Fazenda Agripastos, no município de Palmeira - PR, localizado nas coordenadas de $25^{\circ} 21^{\prime}$ de latitude Sul e $49^{\circ} 56^{\prime}$ de longitude Oeste e altitude de 820 m (8). A Fazenda situa-se no Segundo Planalto, região dos Campos Gerais do Paraná.

O solo foi caracterizado como Argissolo Vermelho-Amarelo, textura média (7), com as seguintes características químicas (Tabela 1).

TABELA 1 - Caracterização química do solo da área experimental, em camadas de 0-10 cm, 10-20 cm e 20-40 cm, Fazenda Agripastos, Palmeira, PR. 1998.

\begin{tabular}{ccccccccccc}
\hline Amostra & $\mathrm{pH}$ & $\mathrm{Al}^{+3}$ & $\mathrm{H}+\mathrm{Al}$ & $\mathrm{Ca}^{+2}+\mathrm{Mg}^{+2}$ & $\mathrm{~K}^{+}$ & $\mathrm{T}$ & $\mathrm{P}$ & $\mathrm{C}$ & $\mathrm{M}$ & $\mathrm{V}$ \\
\hline$(\mathrm{cm})$ & $\left(\mathrm{CaCl}_{2}\right)$ & & & $\left(\mathrm{cmolc} \cdot \mathrm{dm}^{-3}\right)$ & & & $\left(\mathrm{mg}_{\mathrm{dm}}{ }^{-3}\right)$ & $\left(\mathrm{g}_{\mathrm{dm}}{ }^{-3}\right)$ & $\%$ & $\%$ \\
\hline $00-10$ & 4,4 & 0,3 & 5,8 & 4,2 & 0,2 & 10,2 & 6,0 & 19,3 & 6,4 & 43,1 \\
$10-20$ & 4,2 & 0,5 & 6,2 & 3,0 & 0,1 & 9,3 & 1,0 & 17,7 & 13,8 & 33,5 \\
$20-40$ & 4,0 & 0,7 & 6,7 & 2,8 & 0,1 & 9,6 & 1,0 & 12,4 & 19,4 & 30,3 \\
\hline
\end{tabular}

${ }^{1}$ Análises realizadas no Laboratório de Análises de Solos do Departamento de Solos da UFPR. 
A área do experimento teve a primeira interferência para cultivo agrícola em 1959. Em 1976 o solo foi preparado para implantação do sistema plantio direto na palha, e a partir de 1981 foi adotado o plano que intercala nas safras de inverno os cultivos de aveia-preta, cevada e trigo e no verão três anos consecutivos de cultivo da soja e um ano de cultivo do milho, nesse experimento substituído pelo girassol.

O delineamento experimental utilizado foi blocos ao acaso com quatro repetições. Os tratamentos testados foram diferentes doses de nitrogênio: 0,25 , $50,75,100$ e $125 \mathrm{~kg} \mathrm{ha}^{-1}$, na forma de uréia, aplicados em cobertura quando as plantas encontravam-se no estádio $V_{8}, 25$ dias após a emergência, segundo a recomendação da EMBRAPA (3).

O cultivo do girassol foi feito em sistema plantio direto na palha sobre cobertura morta formada pelo cultivo da aveia-preta (Avena strigosa) dessecada uma semana antes da semeadura, por meio de aplicação de 960 g.ha- ${ }^{-1}$ de glyphosate, misturado com 0,5 L.ha-1 de óleo mineral.

A quantidade de matéria seca produzida pela aveia-preta foi estimada em $3400 \mathrm{~kg} \cdot \mathrm{ha}^{-1}$. O fornecimento de nitrogênio foi de $54,4 \mathrm{~kg} \cdot \mathrm{ha}^{-1}$, considerando a média de $1,6 \%$ da palhada (16).

Foi utilizada uma semeadora de grãos, PAR 2800 , apropriada para o sistema plantio direto na paIha, com quatro linhas de plantio distanciadas a 0,90 $\mathrm{m}$ e discos de semeadura recomendados para o cultivo do girassol, regulados para a distribuição de cinco sementes por metro de sulco, visando o estabelecimento de uma população de 50 mil plantas.ha ${ }^{-1}$, considerando o poder de germinação das sementes e perdas totais $(3 ; 24)$.

A semeadura foi realizada em setembro de 1998 com o híbrido M734 recomendado para semeadura no Estado do Paraná (6), que apresenta ciclo tardio, com maturação fisiológica aos 103 dias após a emergência e teor de óleo nos aquênios de aproximadamente $41 \%$ (20). A adubação de base foi feita com $300 \mathrm{~kg} \cdot \mathrm{ha}^{-1}$ de 0-26-26, seguindo a recomendação para semeadura convencional (3), que sugere aplicação de 40 a $80 \mathrm{~kg}$ ha $^{-1}$ destes nutrientes, quando os níveis de fósforo e de potássio forem considerados médios, como na camada $0-10 \mathrm{~cm}$.

A calagem superficial foi realizada antes da semeadura da aveia-preta e, a acidez do solo estava alta na camada de $0-10 \mathrm{~cm}$ e muito alta na camada de $10-40 \mathrm{~cm}$ antes da semeadura do girassol (Tabela 1).

Dois dias antes da execução dos tratamentos, foi feito o sulcamento a $8 \mathrm{~cm}$ de profundidade e distanciados a $20 \mathrm{~cm}$ das linhas de cultivo, utilizando uma adubadeira adaptada para aplicação localizada de nitrogênio em cobertura no cultivo do milho em sistema plantio direto na palha. Após a aplicação dos tratamentos a uréia foi imediatamente incorporada, fechando-se os sulcos com auxílio de enxada.
Cada parcela foi formada por seis linhas com dez metros de comprimento, perfazendo área total de $54 \mathrm{~m}^{2}$, com média de 4,5 plantas. $\mathrm{m}^{-2}$.

Para avaliação do rendimento e seus componentes, do índice de colheita aparente e do teor de óleo nos aquênios foram colhidas todas as plantas de duas linhas centrais, desprezando-se um metro de bordadura nas extremidades das parcelas, com área útil de 14,4 $\mathrm{m}^{2}$.

Foi realizada a aplicação de boro, utilizandose o bórax como fonte, na dose de $1,0 \mathrm{~kg} \cdot \mathrm{ha}^{-1}$ de $\mathrm{B}$ dissolvido previamente em água a $70{ }^{\circ} \mathrm{C}$ e aplicado com pulverizador costal manual, quando as plantas se encontravam no estádio de desenvolvimento $V_{9}$.

Quando as plantas se encontravam no estádio $R_{4}$, foram coletadas folhas do terço superior de cinco plantas por parcela para realização de análise de tecido.

$\mathrm{Na}$ colheita foram realizadas as avaliações: a) população, em plantas $\mathrm{m}^{-2}$, da área útil das parcelas; b) massa de aquênios, em gramas por parcela, para obtenção do rendimento, sendo os valores corrigidos para $11 \%$ de umidade e transformados em kg.ha-1; c) massa média de 1000 aquênios, em gramas, de três amostras de 1000 aquênios por parcela; d) número de aquênios por capítulo, calculado por meio da fórmula: $A / C=[M \times 1000 / M 1000 \times C]$, onde: $A / C=$ número de aquênios por capítulo, $M=$ massa de aquênios na área útil $(\mathrm{g}), M 1000=$ massa de 1000 aquênios (g), C= número de capítulos na área útil; e) índice de colheita aparente (ICA), calculado por meio da fórmula: $I C A=[M S A / M S T+M S A]$, onde: $I C A=$ índice de colheita aparente, MSA= massa seca de aquênios $(\mathrm{g})$, MST = massa seca da parte aérea + massa seca de aquênios $(\mathrm{g})$; f) teor de óleo, em porcentagem, expresso em base seca, análise realizada na EMBRAPA/ Soja.

Os resultados foram submetidos à análise de variância utilizando o programa MSTATC. As variâncias dos tratamentos foram analisadas pelo teste de Bartlett. As variáveis cujas variâncias mostraram-se homogêneas tiveram as médias dos tratamentos testadas por meio do teste F. Quando os resultados revelaram existir diferenças estatisticamente significantes entre as médias de tratamentos, estas foram comparadas pelo teste de Tukey, em nível de $5 \%$ de probabilidade (11)

\section{RESULTADOS E DISCUSSÃO}

A análise de variância demonstrou efeito significativo entre os tratamentos para o teor de nitrogênio foliar. Entretanto, não houve diferença significativa para as variáveis rendimento de grãos, seus componentes e o índice de colheita aparente. (Tabela 2). 
CARVALHO, D.B. e PISSAIA, A. Cobertura nitrogenada em girassol...

TABELA 2 - Médias obtidas para população, rendimento de grãos, massa, número, teor de óleo nos aquênios, índice de colheita aparente e teor de nitrogênio foliar de girassol em função de doses de nitrogênio em cobertura, em sistema plantio direto na palha. Fazenda Agripastos, Palmeira, PR. 1998/991.

\begin{tabular}{|c|c|c|c|c|c|c|c|}
\hline \multirow{2}{*}{$\begin{array}{l}\text { Tratamentos } \\
\left(\mathrm{kg} \text { de N.ha }{ }^{-1}\right)\end{array}$} & \multicolumn{7}{|c|}{ Variáveis } \\
\hline & $\begin{array}{c}\text { População } \\
\text { (plantas.m }{ }^{-2} \text { ) }\end{array}$ & $\begin{array}{c}\text { Rendimento } \\
\text { de grãos } \\
\left(\mathrm{kg} . \mathrm{ha}^{-1}\right)\end{array}$ & $\begin{array}{c}\text { Massa de } \\
1000 \\
\text { aquênios (g) }\end{array}$ & $\begin{array}{l}\text { Aquênios } \\
\text { por } \\
\text { capítulo }\end{array}$ & $\begin{array}{c}\text { Índice de } \\
\text { colheita } \\
\text { aparente }\end{array}$ & $\begin{array}{c}\text { Teor de } \\
\text { óleo nos } \\
\text { aquênio (\%) }\end{array}$ & $\begin{array}{c}\text { Teor } \\
\text { foliar de } \\
\mathrm{N}\left(\mathrm{g} \cdot \mathrm{kg}^{-1}\right) \\
\end{array}$ \\
\hline 0 & 4,3 & 1950 & 68,6 & 440 & 0,34 & 42,0 & $44,8 \quad b$ \\
\hline 25 & 4,6 & 1875 & 66,5 & 417 & 0,34 & 41,9 & $46,5 \mathrm{a} \mathrm{b}$ \\
\hline 50 & 4,7 & 2180 & 67,4 & 499 & 0,35 & 41,7 & 45,7 a b \\
\hline 75 & 4,4 & 2073 & 68,3 & 470 & 0,35 & 42,2 & 49,7 a b \\
\hline 100 & 4,7 & 2062 & 68,2 & 467 & 0,35 & 41,2 & $52,5 a$ \\
\hline 125 & 4,2 & 2179 & 71,1 & 485 & 0,34 & 41,1 & $51,9 a$ \\
\hline \multicolumn{8}{|l|}{ Coeficiente de } \\
\hline Variação & 7,36 & 6,96 & 8,19 & 12,35 & 9,58 & 3,17 & 6,15 \\
\hline
\end{tabular}

${ }^{1}$ Médias seguidas pela mesma letra não diferem entre si em nível de $5 \%$ de probabilidade para o teste de Tukey $(p=0,05)$.

O teor médio de nitrogênio foliar encontrado $\left(48,5 \mathrm{~g} \cdot \mathrm{kg}^{-1}\right)$ é adequado para girassol (2). Apesar da diferença existente no teor foliar, o rendimento não foi alterado.

A aplicação de nitrogênio em cobertura realizada em um solo cultivado em sistema plantio direto na palha desde o ano agrícola de 1976 não provocou diferenças em relação à testemunha com dose zero para o rendimento de grãos, seus componentes, índice de colheita aparente e o teor de óleo nos aquênios.

A importância atribuída à adubação nitrogenada no cultivo do girassol com recomendação de 40 a 60 kg.ha-1 $(3 ; 19)$, não foi evidenciada na situação deste experimento, onde as características do solo e do sistema de cultivo dificultam a determinação da real necessidade de nitrogênio adicional (17).

A decomposição da matéria orgânica deve ter fornecido nitrogênio para o girassol no solo do experimento em conformidade com afirmativas de outros autores $(15 ; 27)$. É possível que exista equilíbrio entre a mineralização e o consumo de nitrogênio pelas plantas e microrganismos, quando o teor de matéria orgânica presente no solo torna-se um indicativo de fertilidade $(10 ; 21)$.

O teor de matéria orgânica do solo (Tabela 1), era de $3,3 \%$ na camada de $0-10 \mathrm{~cm}$ de profundidade. Essa quantidade de matéria orgânica disponibiliza para as plantas cerca de $66 \mathrm{~kg} \cdot \mathrm{ha}^{-1}$ de nitrogênio, considerando que cada $1 \%$ de matéria orgânica no solo fornece $20 \mathrm{~kg} \cdot \mathrm{ha}^{-1}$ de nitrogênio (13).

Observando o rendimento médio obtido (2053 $\mathrm{kg} \cdot \mathrm{ha}^{-1}$ ), é possível entender que as condições edafoclimáticas existentes no local e na época da realização do experimento tornaram desnecessária a aplicação de nitrogênio.

Considerando a sucessão de culturas, onde o cultivo da soja foi realizado durante três anos consecutivos antes da implantação do girassol, a quantidade média de nitrogênio fornecida é equivalente à apli- cação de $72 \mathrm{~kg} \cdot \mathrm{ha}^{-1}$ por cultivo de leguminosa (16).

$\mathrm{O}$ incremento de nitrogênio no solo devido a presença de leguminosas na rotação de culturas reduz a necessidade de aplicações de fertilizantes nitrogenados em várias espécies cultivadas após leguminosas (16; 22). Assim, os resultados encontrados estão de acordo com as conclusões de outros autores e demonstram que a aplicação de nitrogênio não era necessária nas condições do sistema de cultivo utilizado, com alta porcentagem de matéria orgânica no solo, cultivos sucessivos com leguminosas e disponibilização de nitrogênio pela palhada.

O número médio de aquênios foi abaixo do esperado para o híbrido M734, provavelmente influenciado pela disponibilidade hídrica irregular e insuficiente (média de $5 \mathrm{~mm}$ diários), durante a fase de florescimento, que se prolongou por 20 dias devido a temperatura média diária abaixo do ideal para esta fase da cultura $\left(20,2^{\circ} \mathrm{C}\right)$.

O teor de óleo nos aquênios não sofreu alteração mesmo nos tratamentos que forneceram as maiores doses de nitrogênio para o cultivo do girassol. Não foi evidenciada a correlação negativa entre adubação nitrogenada e teor de óleo nos aquênios, sendo que a média encontrada $(41,68 \%)$ é característica do híbrido semeado (6).

\section{CONCLUSÃO}

A adubação nitrogenada em cobertura, nas condições deste experimento, não influencia significativamente o rendimento de grãos, seus componentes, o índice de colheita aparente e teor de óleo nos aquênios de girassol. A quantidade de matéria orgânica do solo, o cultivo sucessivo de leguminosas e o fornecimento de nitrogênio pela palhada, são sugestivos de que a quantidade de nitrogênio disponibilizado é suficiente para o girassol. 


\section{REFERÊNCIAS BIBLIOGRÁFICAS}

1 BAYER, C.; SCHENEIDER, N. G. Plantio direto e o aumento no conteúdo de matéria orgânica do solo em pequenas propriedades rurais no município de Teutônia. Ciência Rural, Santa Maria, v.29, n.1, p.155-166, 1999.

2 BLAMEY, F. P. C.; ZOLLINGER, R. K.; SCHNEITER, A. A. Sunflower production and culture. In: SCHNEITER, A. A. (Ed.) Sunflower tecnology and production. 2 ed. Madison: American Society of Agronomy, 1997. p.595-696. (Agronomy 35)

3 CASTRO, C. de; CASTIGLIONI, V. B. R.; BALLA, A.; LEITE, R. M. V. B. DE C.; KARAM, D.; MELLO, H. C.; GHEDES, L. C. A.; FARIAS, J. R. B. A Cultura do girassol. Londrina: EMBRAPA-CNPSo, 1997. 36p. (Circular Técnica, 13)

4 DEIBERT, E. J. Sunflower production comparisons with conventional and reduced tillage systems. North Dakota Farm Research, v.44, n.5, p.25-29, 1987.

5 DEIBERT, E. J. ; UTTER, R. A. Sunflower growth and nutrient uptake: Response to tillage system, hybrid maturity and weed control method. Soil Science Society of American Journal, Madison, v.53, p.133-138, 1989.

6 EMBRAPA/CNPSo. Informes da avaliação de genótipos de girassol, 1996/97 e 1997. Londrina, 1997. 116p. (EMBRAPACNPSo. Documentos, 110)

7 EMBRAPA. CNPS. Sistema Brasileiro de Classificação de Solos. Rio de Janeiro: EMBRAPA Solos, 1999. 412p.

8 FUNDAĈ̃̃ INSTITUTO AGRONÔMICO DO PARANÁ. Cartas climáticas do Estado do Paraná. Londrina, 1984. 45p.

9 HECKLER, J. C. ; SILVA, P. R. F. da. Sistemas de sucessão e rotação de culturas de estação estival de crescimento. Pesquisa Agropecuária Brasileira, Brasília, v.20, n.9, p.1069-1076, 1985.

10 KOCHHANN, R. A. Alterações das características físicas, químicas e biológicas do solo sob sistema de plantio direto. In: I CONFERÊNCIAANUAL DE PLANTIO DIRETO (1.: Passo Fundo: 1996). Resumos. Passo Fundo, 1996, p.17-25.

11 KOELHER, H. S. Estatística experimental. Curitiba: Universidade Federal do Paraná, 1998, 124p.

12 LATHWELL, D. J.; BOULDIN, D. R. Soil organic matter and soil nitrogen behaviour in cropped soils. Tropical Agriculture, Survey, v.58, p.341-348, 1981.

13 MENGEL, D. B.; NELSON, D. W.; HUBER, D. M. Placement of nitrogen fertilizer for no-till and conventional till corn. Agronomy Journal, Madison, v.74, p.515-518, 1982

14 MUNDSTOCK, C. M.; ZAGONEL, J. Perfil de área foliar de duas cultivares de girassol sob doses e épocas de aplicação de nitrogênio em cobertura. Pesquisa Agropecuária Brasileira, Brasília, v.29, n.6, p.847-851, 1994

15 OLIVEIRA, S. A. Avaliação da disponibilidade de N no solo. Pesquisa Agropecuária Brasileira, Brasília, n.24, v.2, p.131-148, 1989.

16 PÖTTKER, D.; ROMAN, E. Efeito de resíduos de culturas e do pousio de inverno sobre a resposta do milho a nitrogênio. Pesquisa Agropecuária Brasileira, Brasília, v.29, n.5, p.763-770, 1994.

17 RAJKOVIC, Z.; VREBALOV, T.; BOGDANOVIC, D. Method of nitrogen fertilization and yield of sunflower hybrid NS-H-26-RM. In: CONFERENCIA INTERNACIONAL DEL GIRASOL (9.: Córdoba: 1980). Resumos. Córdoba: Instituto Nacional de Investigaciones Agrárias, 1980. p.192-196.

18 RODRIGUES, M. B. KIEHL, J. C. Volatilização de amônia após emprego de uréia em diferentes doses e modos de aplicação. Revista Brasileira de Ciência do Solo, Campinas, n.10, p.37-43, 1986.

19 ROSSI, R. O. Adubação em girassol. São Miguel do Oeste: Santa Catarina, 1991. 31p.

20 ROSSI, R. O. Girassol. Curitiba: Tecnoagro, 1998. 333p.

21 SÁ, J. C. M. Manejo da Fertilidade do Solo no Plantio Direto. Castro: Fundação ABC, 1993. 96p.

22 SÁ, J. C. M. Nitrogênio: Transformações no solo, mobilização e imobilização. In: CURSO SOBRE MANEJO DO SOLO NO SISTEMA DE PLANTIO DIRETO. (1.: Castro: 1995) Anais. Castro: Fundação ABC, 1995. p.204-210.

23 SCHIMIDT, E. ; SILVA, P. R. F da. Efeito da densidade e arranjo de plantas de girassol. Il características agronômicas e interceptação de radiação solar. Pesquisa Agropecuária Brasileira, Brasília, v.21, n.8, 853-863, 1986.

24 SILVA, P. R F. da.; RIZZARDI, M. A.; TREZZI, M. M.; ALMEIDA, M. L. de. Densidade e arranjo de plantas em girassol. Pesquisa Agropecuária Brasileira, Brasília, v.30, n.6, p.797-810, 1995.

25 SILVA, P. R. F. da.; WENDT, W.; ROCHA, A. B. da. Manejo do solo e adubação na cultura do girassol em sucessão à aveia-preta. Pesquisa Agropecuária Brasileira, Brasília, v.32, n.6, p.641-647, 1997.

26 TEIXEIRA, L. A. J.; TESTA, V. M.; MIELNICZUK, J. Nitrogênio do solo, nutrição e rendimento de milho afetados por sistemas de culturas. Revista Brasileira de Ciência do Solo, Campinas, n.18, p.207-214, 1994.

27 TROECH, F. R.; THOMPSON, L. M. Soils and soil fertility. 5. ed. Oxford: Oxford University Press, 1993. 462p.

28 VRÂNCEANU, A. V. El Girassol. Madrid: Mundi Prensa, 1977. 379p.

29 ZAGONEL, J.; MUNDSTOCK, C. M. Doses e época de aplicação de nitrogênio em cobertura em duas cultivares de girassol. Pesquisa Agropecuária Brasileira, Brasília, n.26, v.9, p.1487-1492, 1991. 